\title{
Correction to: An evaluation of risk factors to predict target concentration non-attainment in critically ill patients prior to empiric $\beta$-lactam therapy
}

\author{
Sahand Imani ${ }^{1,2} \cdot$ Hergen Buscher ${ }^{3,4} \cdot$ Richard Day $^{4,5}$. Sheridan Gentili6 . Graham R. D. Jones ${ }^{4,7}$. Debbie Marriott ${ }^{2,4}$. \\ Ross Norris $^{8,9} \cdot$ Indy Sandaradura ${ }^{2,4,10}$
}

Published online: 17 June 2021

(c) Springer-Verlag GmbH Germany, part of Springer Nature 2021

\section{Correction to: European Journal of Clinical Microbiology \& Infectious Diseases (2018) 37:2171-2175 https://doi.org/10.1007/s10096-018-3357-9}

In the originally published version of the article, the author contributions statement that appeared on page 2175 was incomplete.

The correct statement appears below:

Author contributions: SI collected data and assisted with manuscript preparation. HB, DM, RD and RN assisted with study design. GJ assisted with study design and data collection.
SG performed data analysis. IS conceived and designed the study, obtained ethical approval, collected, analysed and interpreted data and prepared the manuscript. All authors reviewed the manuscript.

Publisher's note Springer Nature remains neutral with regard to jurisdictional claims in published maps and institutional affiliations.
The original article can be found online at https://doi.org/10.1007/ s10096-018-3357-9.

Indy Sandaradura

Indy.Sandaradura@health.nsw.gov.au

1 School of Medicine, University of Notre Dame Australia, Sydney, NSW, Australia

2 Department of Clinical Microbiology, SydPath, St Vincent's Hospital, Sydney, NSW, Australia

3 Department of Intensive Care Medicine, St Vincent's Hospital, Sydney, NSW, Australia

4 St Vincent's Clinical School, Faculty of Medicine, University of New South Wales, Sydney, NSW, Australia

5 Department of Clinical Pharmacology and Toxicology, St Vincent's Hospital, Sydney, NSW, Australia
6 School of Pharmacy and Medical Sciences, Sansom Institute for Health Research, University of South Australia, Adelaide, SA, Australia

7 Department of Chemical Pathology, SydPath, St Vincent's Hospital, Sydney, NSW, Australia

8 Discipline of Clinical Pharmacology, School of Medicine \& Public Health, University of Newcastle, Newcastle, NSW, Australia

9 Hunter Medical Research Institute, Kookaburra Circuit, New Lambton Heights, NSW, Australia

10 Centre for Infectious Diseases and Microbiology, Westmead Hospital, Sydney, NSW, Australia 